\title{
Wajdi Mouawad, Assoiffés
}

\section{Veronica Cappellari}

\section{Q OpenEdition}

\section{Journals}

\section{Edizione digitale}

URL: http://journals.openedition.org/studifrancesi/9711

DOI: ERREUR PDO dans /localdata/www-bin/Core/Core/Db/Db.class.php L.34 : SQLSTATE[HY000]

[2006] MySQL server has gone away

ISSN: 2421-5856

\section{Editore}

Rosenberg \& Sellier

\section{Edizione cartacea}

Data di pubblicazione: 1 décembre 2007

Paginazione: 706-707

ISSN: 0039-2944

\section{Notizia bibliografica digitale}

Veronica Cappellari, «Wajdi Mouawad, Assoiffés», Studi Francesi [Online], 153 (LI | III) | 2007, online dal 30 novembre 2015, consultato il 07 janvier 2021. URL: http://journals.openedition.org/studifrancesi/ 9711 ; DOI: https://doi.org/ERREUR PDO dans /localdata/www-bin/Core/Core/Db/Db.class.php L.34 : SQLSTATE[HYO00] [2006] MySQL server has gone away

Questo documento è stato generato automaticamente il 7 janvier 2021.

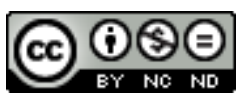

Studi Francesi è distribuita con Licenza Creative Commons Attribuzione - Non commerciale - Non opere derivate 4.0 Internazionale. 


\title{
Wajdi Mouawad, Assoiffés
}

\author{
Veronica Cappellari
}

\section{NOTIZIA}

WAJDI MOUAWAD, Assoiffés, Montréal/Arles, Leméac/Actes-Sud Papiers, 2007, pp. 39.

1 Assoiffés di Wajdi Mouawad, autore e regista di origine libanese emigrato in Québec negli anni Novanta, è la terza opera di un ciclo drammatico, interamente dedicato al jeune publique, inaugurato nel 1996 con Alphonse (Montréal, Leméac), e proseguito, nel 2003, con Pacamambo (Montréal/Arles, Leméac/Actes Sud-Papiers), opere che coinvolgono gli adolescenti in un vero e proprio viaggio iniziatico sospeso tra realtà, sogno e immaginazione.

2 Assoiffés, portata per la prima volta in scena in Québec il 12 ottobre 2006 al Théâtre Lionel-Groulx di Sainte-Thérèse-de-Blainville, per la regia di Benoît Vermeulen, rappresenta i dubbi, le preoccupazioni, le incertezze, le speranze e le disillusioni che normalmente incontrano gli adolescenti nel passaggio dall'infanzia all'adolescenza e poi all'età adulta. La vicenda si svolge nella Montréal del xxI secolo. Boon, un antropologo criminale incaricato di scoprire il mistero che si cela dietro il ritrovamento dei cadaveri di un uomo e di una donna, rinvenuti avvinghiati l'uno all'altra nel fiume Saint-Laurent, identifica il corpo del ragazzo come quello del suo amico d'infanzia Murdoch, di cui si erano perse le tracce nel febbraio del 1991. Il riconoscimento del corpo di Murdoch porta Boon a riandare con i propri ricordi all'infanzia, a quei lontani giorni che precorsero la scomparsa dell'amico. Fantasticando sulle proprie future sorti di scrittore, allora egli aveva composto, a nome del fratello maggiore, una pièce di teatro nella quale veniva illustrata l'infelicità di Norvège, una fanciulla ossessionata dal proprio aspetto fisico, che sceglieva di allontanarsi dalla società chiudendosi in un ostinato mutismo. La creazione di Boon, presentata pubblicamente in sede scolastica, non aveva riscosso il successo sperato; di fronte all'incomprensione generale, l'unico studente che era rimasto commosso ed emozionato dall'opera era stato proprio Murdoch, il quale si era riconosciuto nel personaggio di Norvège. Realtà e finzione 
entrano così in contatto e si intrecciano, dando vita a due distinti piani narrativi, per altro indissolubili, ma che resterebbero incomprensibili (o inconclusi) ove mancasse quel legame che li salda strettamente.

3 L'opera di Wajdi Mouawad getta uno sguardo di adulto su alcune problematiche degli adolescenti, segnati troppo spesso dalla sofferenza, dalla mancanza di amore e di fiducia in sé stessi, dalla scarsità di forti punti di riferimento che sappiano dare un senso alla loro esistenza. Il drammaturgo sollecita dunque una riflessione sulla nostra società e sull'importante ruolo che l'arte teatrale può svolgervi. In un momento in cui $\mathrm{i}$ valori vanno perdendo consistenza, sopraffatti da modelli sempre più consumistici $\mathrm{e}$ privi di reale valore, l'opera drammatica può risvegliare le menti e gli animi, divenendo uno strumento attraverso il quale esprimere e trasmettere i propri sentimenti. Il teatro non deve perciò soltanto rappresentare la società, ma interagire con essa per favorire una migliore crescita umana e culturale attraverso un contributo pedagogico e didattico. 